\title{
Space Design of Rural Bed and Breakfast in the Context of Ecological Aesthetics
}

\author{
Jingsi Li' ${ }^{1}$ Chaoyi You ${ }^{2 *}$ \\ ${ }^{1}$ Art College of Southwest Minzu University, Chengdu, China \\ ${ }^{2}$ Architecture and Urban Planning College of Southwest Minzu University, Chengdu, China \\ Email: *651645399@qq.com
}

How to cite this paper: Li, J. S., \& You, C. Y. (2020). Space Design of Rural Bed and Breakfast in the Context of Ecological Aesthetics. Open Journal of Social Sciences, 8 , 454-460.

https://doi.org/10.4236/jss.2020.84033

Received: April 2, 2020

Accepted: April 21, 2020

Published: April 24, 2020

Copyright $\odot 2020$ by author(s) and Scientific Research Publishing Inc. This work is licensed under the Creative Commons Attribution International License (CC BY 4.0).

http://creativecommons.org/licenses/by/4.0/

(c) (i) Open Access

\begin{abstract}
In China, with the continuous development of rural economy and the promotion of beautiful rural strategy, rural modern tourism has become the main trend in promoting the development of rural areas. As an important technology and main carrier to lead and develop rural modern tourism in the development process of rural modern tourism, the space design of rural bed and breakfast plays a vital role in rural modern tourism in China. In this paper, considering that the leading role of Chinese traditional aesthetics is very important for the development of the space design of rural bed and breakfast in China, the design idea is clarified according to the principle of beautiful space design and traditional aesthetic logic, and the development path of the construction of modern space design of rural bed and breakfast in the context of ecological aesthetics is put forward by fully combining the actual needs of the development of modern rural tourism in China, that is, the architectural connotation and practice with the characteristics of Chinese rural human history are combined on the basis of scientific and reasonable development of the space design of rural bed and breakfast, so that the villagers can establish a correct ecological outlook on nature and a leisure lifestyle in line with ecological aesthetics, aiming to provide reference for the development of modern space design of rural bed and breakfast in China.
\end{abstract}

\section{Keywords}

Ecological Aesthetics, Rural Bed and Breakfast, Space Design

\section{Introduction}

With the gradual improvement of economic level in recent years, people gradually turn from pursuing material to pursuing spiritual feelings and spiritual 
needs. In this context, rural tourism has gradually become a nutrient and necessity in people's life. With the rise of rural tourism, the development of rural bed and breakfast has been driven, and more and more people participate in the construction of rural bed and breakfast. However, in order to provide consumers with a more comfortable environment in a sense, many developers and builders in the process of construction and development of rural bed and breakfast pursue visual beauty unilaterally, and even sacrifice the surrounding ecological environment in order to promote the development of social economy. However, in his article On Ecological Aesthetics published in 1994, Professor Li Xinfu said: "the beauty of ecological environment is the highest value of all the beauty that nature has given to human beings after the universe has been generated" ( $\mathrm{Li}$, 1994).

Nowadays, every country in the world advocates protecting the ecological environment in different ways. As the design of visual beauty, the design of rural residential space needs to be highly integrated with the ecological environment. It is not advisable to pursue economic benefits blindly and neglect human and natural benefits. The rural residential space design which is more in line with the current social environment should be the rural residential space design under ecological aesthetics.

\section{An Overview of Ecological Aesthetics}

Ecological aesthetics is a comprehensive subject integrated by ecology and architectural aesthetics (Gan \& Feng, 2012). Among them, ecology is considered as a discipline that studies the relationship between organisms and their natural environment, while aesthetics is considered as a social philosophy technology discipline that explores and studies the relationship between human beings and their real aesthetic environment. There is a special combination point in the research of these two comprehensive disciplines on the relationship between human beings and nature and between human beings and their living environment, in which ecological aesthetics exists. As for the subject of ecological aesthetics, Zeng Fanren (2005) believed that "ecological aesthetics is an aesthetic concept with Chinese characteristics". At the same time, Han Dexin (2003) believed that "ecological aesthetics refers to the aesthetic theoretical form that takes ecology as the thinking method and applies it to the aesthetic field to establish a new one to meet the needs of social development". Therefore, the reason why this paper studies the space design of rural ecology and the bed and breakfast from the perspective of the space design of rural ecological aesthetics is to make it better adapt to the needs of the current economic development, social development, and the coordinated development of economy and culture. The space design based on the concept of ecological civilization has gradually developed into the concept and purpose of the space design of the rural bed and breakfast, which is to strive to create a sustainable modern rural residential space landscape and interior architecture space design. 


\section{The Concept of Rural Bed and Breakfast}

According to the geographical location, the house is divided into urban bed and breakfast and rural bed and breakfast (Wang, Bai, \& Ye, 2019). Among them, the rural bed and breakfast refer to the rural "Agritainment" with relatively strong rural culture, better regional resources, original human feelings and unique local folk activities (Wang, Bai, \& Ye, 2019). However, compared with the traditional sense of "Agritainment", the rural bed and breakfast not only has a more prominent and novel form of development, but also has more perfect services and facilities. However, the design of rural bed and breakfast is usually based on "family type", that is, the host of bed and breakfast is the receptionist and server, which is different from other hotels with professional team $(\mathrm{Lu}, 2019)$ and professional service mode. Highlighting the cultural connotation of rural tourism and promoting the development of local scenic spots or other regional characteristic resources are becoming the goal of rural bed and breakfast, the innovative carrier of rural tourism (Guo, 2018). The biggest advantages and characteristics of rural bed and breakfast are its regional characteristics, cultural atmosphere and host feelings.

\section{The Existing Problems of the Rural Bed and Breakfast}

Most of the rural bed and breakfast are built by the villagers using their idle houses (Wang, Bai, \& Ye, 2019). The construction area of rural bed and breakfast combines the vitality of local agricultural production to provide tourists with a living mode of tourism under the local environment. There are problems in the rural operation mechanism, the villagers have poor information and design experience, and the basic municipal facilities are not perfect, so there are the following problems in the rural bed and breakfast:

\subsection{Inadequate Facilities}

In the process of rural construction, not only the cement roads in the relatively backward areas have not been repaired, but even more perfect villages can only meet the needs of basic infrastructure. The local culture and characteristics of the village are still in a blank state and even have the trend of gradual loss, the village lacks the original natural local flavor, and only the function of infrastructure is considered, but the pursuit of aesthetic feeling is lacking. Due to the commercial use of bed and breakfast, most rural bed and breakfast show the problem of insufficient infrastructure, for example, the phenomenon of private construction of independent toilets required by the commercial rooms reconstructed is serious (Wang, Bai, \& Ye, 2019), and most of the bed and breakfast fail to meet the basic public building specifications and fire protection requirements. The construction of infrastructures such as water supply, power supply and heating needs to be planned and implemented by the rural administrative departments in a unified way, which is not only the most important infrastructure to protect the villagers, but also a part of ensuring people's livelihood. In 
this regard, we should learn from the foreign experience for the cultural and historical extension of rural infrastructure, as well as the preservation and careful maintenance of many historical relics. For example, the infrastructure such as rural road transportation in Britain ranks higher than that of the city in some aspects. The overall planning of rural infrastructure started earlier and specific laws and regulations have been formulated by the government. At the same time, the government has relatively high requirements for transportation facilities, water supply, power supply, heating and other aspects. In addition, the government also charges a certain amount of maintenance fees to protect and repair historical buildings in rural areas.

\subsection{Lack of Use of Native Materials}

It is necessary to guide the traditional aesthetic concept and environmental protection consciousness of the villagers. The remote geographical location leads to the villagers' conformity and blindness in selecting materials. However, as the most important part of the design of the bed and breakfast, different building materials can directly or indirectly express and create different tone aesthetic feeling and texture in the process of design and construction, represent different culture and era characteristics, create different bed and breakfast space and form, and create different feeling and atmosphere. Especially, the use of local building materials is an indispensable part of the design of modern rural bed and breakfast, which is perfectly presented in the construction of rural bed and breakfast with its unique value and charm. In addition to being able to express and highlight the local regional characteristics such as natural environment, human history and customs, it can also express the modern urban residents' desire to return to ecology and protect nature and local feelings in the design, so that the architectural culture of rural bed and breakfast can be more fully reflected through this important carrier. However, the selection and application of local materials in the process of new construction or renovation of rural bed and breakfast are completely ignored.

\subsection{Lack of Experience Design}

Villagers are not very clear about the concept of bed and breakfast. The foundation of bed and breakfast is experience design. Different from hotels, bed and breakfast needs to fully explore its resource advantages and develop unique experience products. However, in terms of products, it is not required to produce a large number of specific products in a large number of ways, but to produce them in a more creative way, that is, to provide more personalized customization, so that the unique needs of customers can be met. At present, there is a serious homogenization phenomenon of bed and breakfast, most of which are lack of industrial design, industrial positioning, and industrial characteristics.

\subsection{Weak Ecological Consciousness}

There are very limited platforms and propaganda means for the education of 
rural ecological protection. Because the local villagers are the main group of building individual rural bed and breakfast in rural areas, they lack funds and awareness of natural ecological protection, and their understanding and cognition of the relationship among natural environment, rural buildings and bed and breakfast is particularly one-sided, so that the original ecology and natural landscape of the rural environment are usually ignored in the traditional design of rural bed and breakfast, the comprehensive application of the original terrain in the design of rural bed and breakfast cannot fully adapt to the surrounding environment, and the natural resources are seriously wasted. At the same time, people are also facing a series of problems and challenges brought by the destruction of natural ecological environment.

\section{Application of Ecological Aesthetics in the Construction of Rural Bed and Breakfast}

\subsection{A Design Management System That Conforms to the Benign Cycle of the Local Ecological Environment Should Be Established}

The design of ecological and environmental protection concept has gradually become the concept and purpose of the interior environment design of rural bed and breakfast. To build an interior design system that can not only meet the surrounding environment, but also can be in a virtuous cycle cannot be achieved by simply designing or using all kinds of green building materials, which involves the basic concepts and design ideas of interior environment design and the creation of space environment atmosphere. In the design process, according to the different physique, living habits and lifestyle of the tenants, the design of daylighting, ventilation and lighting should be carried out scientifically and reasonably from reality. Moreover, the outdoor design elements should be directly or indirectly quoted into the interior space as much as possible in the design process. At the same time, more emphasis is placed on the application of natural elements, aiming to enable the experiencer and user to better perceive nature, get close to nature and return to the countryside through their elements and materials.

\subsection{Rural Bed and Breakfast, with Distinctive Characteristics, Is Built on the Understanding and Respect of the Heavy History}

The unique features of a local environment always give special characteristics to its culture. It is precisely because different regions have different forms of cultural habits that the diversity of Chinese traditional culture is created. Many rural villages are ecological existence formed through historical and cultural accumulation (Wang, 2008). In addition to meeting the local feelings of consumers, integrating regional culture into the design process of rural bed and breakfast can also play a role in protecting and inheriting local culture. Therefore, when the rural bed and breakfast is designed, first of all, the local culture should be fully understood and felt, the regional characteristics should be found, and 
the most representative cultural symbols should be selected; Secondly, in the process of design and construction, the local customs, folk customs and regional characteristics should be fully combined, and the design techniques should be avoided to be too rigid, so that the rural houses can be endowed with new colors and vitality.

\subsection{Ecological Resources Should Be Used Reasonably to Build Ecological Rural Bed and Breakfast}

Ecological design should be carried out according to local conditions. The vegetation and its planting method should be reasonably selected in combination with the ecological characteristics of the vegetation, the local original landform, climate and environment should be respected, the precious trees should be preserved, and the original water body should be maintained (Cao \& Jin, 2019), aiming to combine with the original natural resources in the overall design. The ecological environment should be designed reasonably according to the local environmental conditions, such as using the factors including the reasonable trend of mountains, the reasonable flow direction of water, the reasonable types of forests, the reasonable layout of villages and so on to design and plan the transformed bed and breakfast, in order to make its appearance be able to integrate into the diversified natural environment texture as the natural growth.

\subsection{Correct Ecological Aesthetic Consciousness Should Be Set up to Build a Harmonious and Beautiful Home}

As early as in ancient Chinese philosophy, there have been abundant ecological thoughts, such as the benevolence advocated by Confucianism and the Dao emulates nature advocated by Taoism. As there is no substitute for the construction of ecological environment in China, the value of fully respecting nature, protecting nature, conforming to nature and the concept of ecological social civilization must be firmly established in the process of planning and design to promote the development of sustainable circular economy. At the same time, all levels of government departments and enterprises need to further improve the legislation of environmental protection system and strengthen the enforcement of environmental management.

\section{Conclusion}

In a word, regardless of the level of social and economic development, a series of problems brought about by the environment cannot be ignored. Since ancient times, protecting environment and respecting nature have been the main ideas advocated. To protect the environment effectively and to promote the balanced development of rural or urban ecology should be taken as the primary premise of all design and environmental construction. In rural residential design, the original of regional culture should be grasped at all times, and the local historical and cultural features, folk customs should be respected and understood, so that they can be more reasonable used in the design. At the same time, in the process 
of design, the surrounding ecological resources should be used reasonably, and the awareness of ecological aesthetics should be correctly established. A better ecological balance mechanism which is in line with the harmony and development of modern human society should be better established and supported among individuals, society and environment by using the form and language of environmental design. Therefore, it is believed that the new generation of people in the future will have a stronger sense of socialist ecological protection and a new concept of socialist life.

\section{Acknowledgements}

This project is funded by the graduate innovative scientific research project [grant number: CX2019SZ187] of Southwest University for nationalities.

\section{Conflicts of Interest}

The authors declare no conflicts of interest regarding the publication of this paper.

\section{References}

Cao, Z., \& Jin, X. (2019). Study on the Diversified Landscape Design Strategy of Rural Bed and Breakfast from the Perspective of Inheriting Regional Culture. Research in Arts Education, No. 9, 108-111.

Gan, S., \& Feng, S. (2012). On Contemporary Ecological Architecture and Its Aesthetic Characteristics. Architecture \& Culture, No. 12, 100-102.

Guo, F. (2018). Problems and Countermeasures in the Development of Rural Bed and Breakfast under the Background of Beautiful Rural Construction. Rural Science and Technology, No. 12, 21-22.

Han, D. (2003). Contemporary Chinese Aesthetics: towards Ecological Aesthetics. Journal of Shandong University of Technology (Social Sciences Edition), No. 6, 23-27.

Li, X. (1994). On Ecological Aesthetics. Social Sciences in Nanjing, No. 12, 53-58.

Lu, L. (2019). On the New Trend of Thought in the Space Design of Bed and Breakfast under the National Targeted Poverty Alleviation Policy. Art Science and Technology, 32, 242-243.

Wang, C., Bai, X., \& Ye, C. (2019). On the Sustainability of Rural Bed and Breakfast. Create Living, No. 3, 59-60.

Wang, Y. (2008). Aesthetic Cognition of Rural Ecology. Jiangxi Social Sciences, No. 7, 195-198.

Zeng, F. (2005). Ecological Aesthetics-A Contemporary Aesthetic Concept with Chinese Characteristics. Chinese Culture Research, No. 4, 1-5. 